\title{
Composição florística e síndromes de polinização e de dispersão da mata do Sítio São Francisco, Campinas, SP, Brasil ${ }^{1}$
}

\author{
Luiza Sumiko Kinoshita ${ }^{2,4}$, Roseli Buzanelli Torres ${ }^{3}$, Eliana Regina Forni-Martins², Tatiana Spinelli², \\ Yu Jie $\mathrm{Ahn}^{2}$ e Sábata Silva Constâncio ${ }^{3}$
}

Recebido em 23/07/2004. Aceito em 12/09/2005

\begin{abstract}
RESUMO - (Composição florística e síndromes de polinização e de dispersão da mata do Sítio São Francisco, Campinas, SP, Brasil). Foi realizado o levantamento florístico da floresta estacional semidecídua localizada no Sítio São Francisco, bem como a caracterização das síndromes de polinização e de dispersão das espécies. Foram encontrados um total de 46 famílias, 116 gêneros e 148 espécies (50 árvores, 35 lianas, 26 arbustos e 37 ervas). As famílias com maior riqueza de espécies arbóreas foram Euphorbiaceae (8), Fabaceae (7), Meliaceae (6) e Rutaceae (5). Entre as lianas, as famílias mais ricas foram Bignoniaceae (13), Sapindaceae (5) e Malpighiaceae (3); entre as herbáceas, Poaceae (8) e Asteraceae (5); e entre as arbustivas, Piperaceae (7) e Rubiaceae (5). As síndromes de polinização e de dispersão mais freqüentes foram melitofilia (73\%) e zoocoria (63\%), ambas predominantes no sub-bosque, sendo que algumas espécies apresentaram mais de uma síndrome de polinização. A análise de similaridade com outros sete fragmentos do município mostrou a mata do Sítio São Francisco em posição intermediária entre as formações higrófilas e as estacionais semidecíduas, e a ocorrência de algumas espécies exclusivas de árvores e de lianas.
\end{abstract}

Palavras-chave: floresta estacional semidecídua, fragmento florestal, interações animal×planta

\begin{abstract}
Floristic composition and pollination and dispersion syndromes in the Sítio São Francisco forest, Campinas, São Paulo State, Brazil). A floristic survey of the seasonal semi-deciduous forest located in the Sítio São Francisco was undertaken, together with studies of pollination and dispersion syndromes of the species. A total of 46 families, 116 genera and 148 species (50 trees, 35 lianas, 26 shrubs and 37 herbs) was found. The richest families in number of arboreal species were Euphorbiaceae (8), Fabaceae (7), Meliaceae (6) and Rutaceae (5). The lianas were distributed mainly in the following families: Bignoniaceae (13), Sapindaceae (5) and Malpighiaceae (3), while in the herbaceous plants, the richest families were Poaceae (8) and Asteraceae (5), and among the shrubs were Piperaceae (7) and Rubiaceae (5). The most frequent pollination and dispersion syndromes were respectively, melittophily (73\%) and zoochory (63\%), both predominating in the sub-arboreal stratum. More than one type of pollination syndrome was observed in some species. Comparing data from this study with seven surveys carried out in the municipality of Campinas, Sítio São Francisco forest showed an intermediate position between the hygrophilous formations and the seasonal semi-deciduous forests as well as the occurrence of some exclusive arboreal and lianas species.
\end{abstract}

Key words: seasonal semideciduous forest, forest fragment, animal×plant interactions

\section{Introdução}

As formações florestais do Domínio da Mata Atlântica paulista compreendem a Floresta Ombrófila Densa, a Floresta Ombrófila Mista e a Floresta Estacional Semidecídua que, em conjunto, ocupam atualmente apenas $14,94 \%$ da sua área original. A redução da cobertura florestal original ainda continua, com uma taxa de desmatamento de $1,65 \%$ no período de 1995 a 2000 (Fundação SOS Mata Atlântica \&
INPE 2002). Os remanescentes da Floresta Estacional Semidecídua do interior do Estado estão esparsamente distribuídos em pequenas áreas que diminuem a cada ano, sendo vários os fatores que contribuem para o desmatamento, como a facilidade de acesso, as pressões agropecuárias e imobiliárias, e os incêndios. Estudos realizados nessas florestas (Pagano \& Leitão Filho 1987; Pagano et al. 1987; Gandolfi et al. 1995), enfocando as espécies arbóreas, têm apontado diferenças florísticas conspícuas e variações na

\footnotetext{
1 Programa de Ensino do Projeto Flora Fanerogâmica do Estado de São Paulo (Fapesp 97/02322-0)

2 Universidade Estadual de Campinas, Instituto de Biologia, Departamento de Botânica, C. Postal 6109, CEP 13083-970, Campinas, SP, Brasil

3 Instituto Agronômico de Campinas, Núcleo de Pesquisa e Desenvolvimento do Jardim Botânico, C. Postal 28, CEP 13001-970, Campinas, SP, Brasil

4 Autor para correspondência: luizakin@unicamp.br
} 
estrutura fitossociológica entre florestas relativamente próximas e até mesmo entre áreas contínuas de uma mesma floresta. Essa heterogeneidade entre fragmentos pode decorrer de variações das condições ambientais, das preferências ecológicas das espécies e de diversos graus de perturbação provocados pelo homem (Bertoni \& Martins 1987; Torres et al. 1994). Cada fragmento apresenta particularidades históricas e diferentes estados de preservação, refletidos em sua composição florística e estrutural, tornando-os únicos, donde a importância da sua conservação para a manutenção da biodiversidade (Santos \& Kinoshita 2003).

Em Campinas, as causas mais remotas da drástica redução da vegetação original estão vinculadas à história do surgimento do município e sua ocupação agrícola, enquanto as causas atuais estão associadas ao crescimento desordenado da cidade e à crescente pressão imobiliária (Santos 2002). Serra Filho et al. (1974) já apontavam, na década de 1970, que apenas $2,16 \%$ da área do município eram cobertos por vegetação natural, sendo $0,67 \%$ de mata, $0,80 \%$ de capoeira, $0,27 \%$ de campo cerrado e $0,42 \%$ de cerrado. A vegetação remanescente ocupa atualmente cerca de $2,55 \%$ a $3 \%$ da área do município (D.A. Santin, dados não pulicados; Fundação SOS Mata Atlântica \& INPE 2002). Até o presente, os remanescentes do município estudados foram: mata da Fazenda São Vicente (Bernacci \& Leitão Filho 1996), mata da Reserva Municipal de Santa Genebra (Morellato 1995a, 1995b; Salis et al. 1996), mata do Ribeirão Cachoeira (Santos \& Kinoshita 2003), mata Santa Elisa (Rodrigues et al. 2004), mata paludícola do Instituto Agronômico de Campinas (Torres et al. 1994), dois fragmentos de mata paludícola localizados ao sul da Reserva de Santa Genebra (Toniato et al. 1998; A.P. Spina, dados não publicados; Spina et al. 2001), e remanescentes localizados na área urbana como o Bosque dos Jequitibás (Matthes et al. 1988), Bosque dos Alemães (Cielo Filho \& Santin 2002) e Bosque São José (Santin, com. pess.).

Os primeiros estudos sobre plantas herbáceas e arbustivas de sub-bosque foram desenvolvidos na Europa (Martins 1991). Apesar de constituir um importante componente florístico, estrutural e funcional na floresta tropical, ainda são pouco numerosos os trabalhos desenvolvidos no Brasil que incluem a coleta de espécies arbustivas, herbáceas e de lianas, como os de Citadini-Zanette (1984), Cestaro et al. (1986), Citadini-Zanette \& Baptista (1989), Salis et al. (1996), Morellato \& Leitão Filho (1998), Müller \& Waechter
(2001) e Negrelle (2002). Alguns trabalhos enfocando as espécies arbóreas também incluíram a coleta assistemática de lianas, como os de Bernacci \& Leitão Filho (1996) e A.P. Spina (dados não publicados).

O conhecimento florístico e fitossociológico das florestas tropicais e o estudo das interações das plantas com os animais (polinização e dispersão, por exemplo) são fundamentais para a compreensão da estrutura e da dinâmica das comunidades e seu processo de regeneração, constituindo importantes ferramentas para a conservação. Esses estudos ajudam a compreender as consequiências da fragmentação para as comunidades animal e vegetal, e permitem minimizar seus efeitos negativos.

Diferentes autores (McCall \& Primack 1992; Herrera 1996; Rozzi et al. 1997; Herrera 1998) têm questionado o valor preditivo das síndromes de polinização, pois encontraram que a maioria das espécies de plantas apresenta muitos polinizadores generalistas. Entretanto, o conceito de síndromes, conforme Faegri \& Pijl (1976), Dafni (1982) e Pijl (1982) é especialmente interessante quando aplicado às comunidades, e constitui uma importante ferramenta para uma primeira abordagem nesse tipo de estudo, como utilizado nos trabalhos de Spina et al. (2001) e L.F. Yamamoto (dados não publicados).

As várias síndromes de polinização sensu Faegri \& Pijl (1976) são encontradas em todas as florestas tropicais, e relativamente poucas espécies são anemófilas (Bawa 1990). Segundo Bullock (1994), em muitas espécies de plantas pode ocorrer um sistema de polinização misto - ambofilia - incluindo correntes de vento e insetos como vetores obrigatórios de pólen. Apenas a análise da morfologia floral, muitas vezes, não é indicativa da ocorrência de ambofilia, que para o autor estaria subestimada, assim como a anemofilia. Segundo Bawa (1990), a maior diversidade de sistemas de polinização é encontrada no sub-bosque, possivelmente devido ao grande número de espécies de plantas nesse estrato. Nas florestas tropicais também ocorrem todas as síndromes de dispersão sensu Pijl (1982), sendo a mais freqüente a zoocoria, seguida da anemocoria e da autocoria (Howe \& Smallwood 1982). Existe uma distribuição espacial não aleatória das síndromes de dispersão e de polinização, podendo ocorrer tanto a estratificação vertical como a diferenciação da borda em relação ao interior das matas (Roth 1987; Smith 1973).

Os objetivos desse estudo foram conhecer a composição florística de um fragmento de Floresta Estacional Semidecídua no município de Campinas, 
considerando todos os hábitos, e investigar a ocorrência e a distribuição das síndromes de polinização e de dispersão.

\section{Material e métodos}

Área de estudo - O fragmento estudado situa-se no Sítio São Francisco, próximo à área urbana e à rodovia Moji-Mirim-Campinas (SP 340), nas coordenadas $22^{\circ} 48^{\prime} \mathrm{S}$ e $47^{\circ} 02^{\prime} \mathrm{W}$ (Fig. 1). É um fragmento de 3,27 ha, entre 585 e $605 \mathrm{~m}$ de altitude, com uma área alagada na baixada, onde existem nascentes. A mata é cortada por uma trilha no sub-bosque, no sentido NE-SO. O solo é Podzólico Amarelo (Oliveira et al. 1977) ou Argissolo Vermelho-Amarelo Distrófico (Embrapa 1999). O clima da região de Campinas, segundo a classificação de Koeppen (1948), é Cwatropical, com duas estações bem definidas, caracterizadas por um inverno seco não rigoroso e um verão quente e chuvoso. A precipitação média anual é de $1.409 \mathrm{~mm}$ e a temperatura média, $20,3{ }^{\circ} \mathrm{C}$ (Mello et al. 1994).

A mata do Sítio São Francisco é pouco perturbada, com estratificação vertical bem definida e dossel fechado na sua maior parte. Lianas são comuns na borda e em clareiras e, em alguns pontos,

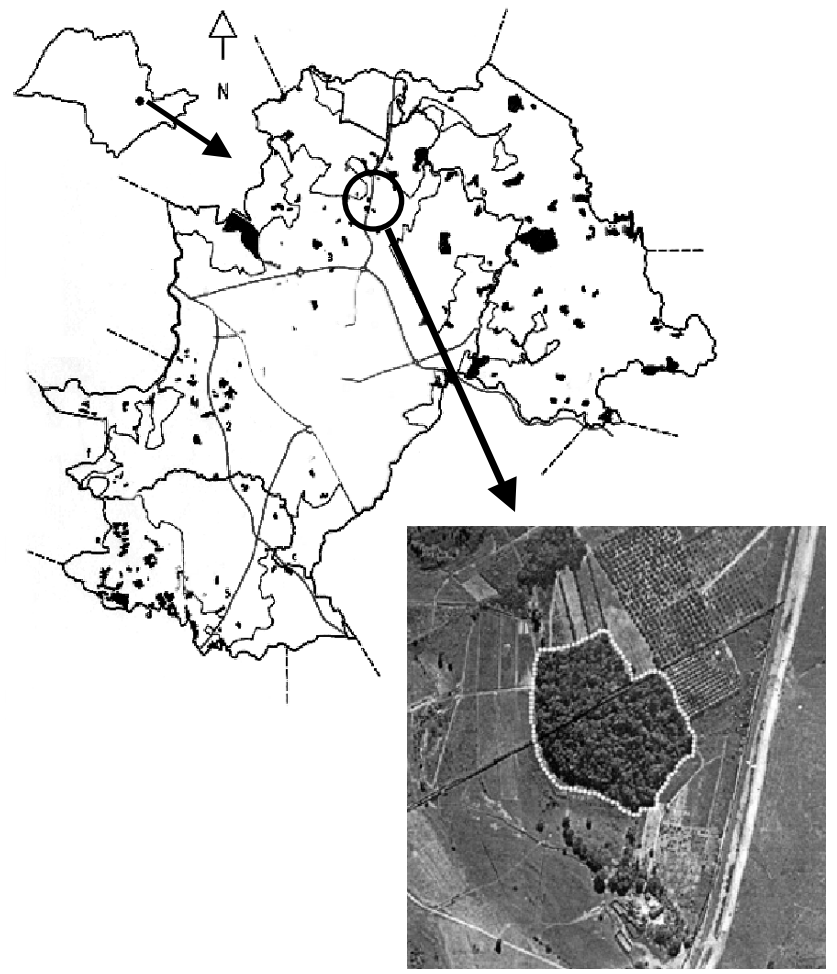

Figura 1. Mapa do Município de Campinas, SP, Brasil, com os remanescentes de vegetação nativa representados em preto, e vista aérea da mata do Sítio São Francisco. descaracterizam sua estratificação. A área tem sido protegida desde 1950, especialmente da ação do gado e de queimadas. Na década de 1970 sofreu o impacto da duplicação da rodovia SP-340 e, em 1988, um princípio de queimada, limitado a um trecho da borda, rapidamente controlado (Dutilh, com. pess.).

Estudo florístico e síndromes de polinização e dispersão - As coletas de material botânico foram realizadas a cada 15 dias, de março/1999 a março/2000, por meio de caminhadas por toda a área, inclusive na borda. Foram coletadas amostras de árvores com DAP $\geq 5 \mathrm{~cm}$, arbustos, lianas e ervas. A freqüência das coletas e de observações foi intensificada nos períodos de maior floração e frutificação, durante a primavera e o verão. Foram considerados três ambientes principais de ocorrência das espécies: estrato superior (dossel e sub-dossel - de 7 a $20 \mathrm{~m}$ de altura), sub-bosque (até $7 \mathrm{~m}$ de altura) e beira da mata (da borda até cerca de $10 \mathrm{~m}$ para o interior da mata). As espécies foram classificadas segundo seu hábito em: árvore, arbusto, arbusto escandente, erva e liana, conforme Font Quer (1965) e Radford et al. (1974).

A identificação foi feita com o auxílio de literatura especializada e por comparação com exemplares depositados no acervo dos herbários UEC e IAC, onde foram incorporados os materiais em estágio reprodutivo. Foi adotada a proposta de classificação de APG II (2003) para as famílias e os nomes dos autores das espécies foram abreviados segundo Brummitt \& Powell (1992).

A caracterização e a descrição das síndromes de polinização e de dispersão foram baseadas na análise de flores e frutos, que foram coletados e preservados em álcool 70\%. Características como cor, odor e presença de néctar foram anotadas diretamente no campo. Os critérios para caracterizar as síndromes de polinização consideraram a morfologia, a cor e o odor da flor, além dos recursos (néctar, pólen, odor, resina, óleo) oferecidos aos agentes bióticos (Faegri \& Pijl 1976). Para a caracterização das síndromes de dispersão, foram considerados o tamanho, a cor e a morfologia dos diásporos, incluindo ornamentações e estruturas acessórias atrativas aos agentes bióticos (Pijl 1982). No caso da dispersão por animais, foi considerada apenas a categoria mais abrangente de zoocoria, sem caracterização do agente específico. Somente foram caracterizadas as síndromes de polinização e de dispersão para as espécies observadas em floração ou frutificação durante os trabalhos de campo. Desse modo, o número de espécies analisadas 
foi menor que o total amostrado no levantamento florístico. Para algumas espécies foram atribuídas mais de uma síndrome de polinização ou de dispersão, e por esse motivo a soma das frequiências das síndromes foi maior que $100 \%$.

Foi realizada a comparação florística entre o conjunto de espécies arbóreas encontradas no presente estudo e outros sete levantamentos realizados no município de Campinas. Foi empregado o índice de similaridade de Jaccard (Pielou 1984) e as relações de similaridade foram feitas por meio da análise de agrupamento por UPGMA com o programa FITOPAC-SHELL versão 1.5 (Shepherd 2004). Dado o pequeno número de estudos no município para as lianas (Tab. 2), a porcentagem das espécies comuns aos fragmentos foi obtida diretamente a partir das listagens florísticas.

\section{Resultados}

Composição florística - Foram encontradas 148 espécies (seis indeterminadas) e 116 gêneros (três indeterminados) distribuídos em 46 famílias (Tab. 1). Cerca de $6 \%$ das espécies não puderam ser identificadas. No estrato superior, sub-bosque e beira de mata foram encontradas 50 espécies arbóreas distribuídas em 38 gêneros e 22 famílias. Foram observadas 37 espécies herbáceas pertencentes a 34 gêneros e 18 famílias, e 26 espécies arbustivas de 18 gêneros e 12 famílias. As espécies herbáceas e arbustivas ocorreram preferencialmente no sub-bosque e, secundariamente, na beira da mata. Foram identificadas 35 espécies de lianas, pertencentes a 29 gêneros e 14 famílias, a maioria no estrato superior e beira da mata.

As famílias com maior número de espécies arbóreas foram Euphorbiaceae (8), Fabaceae (7), Meliaceae (6) e Rutaceae (5) que, juntas, constituíram cerca de $46 \%$ do total amostrado. As famílias com maior número de espécies lianas foram: Bignoniaceae (13), Sapindaceae (5) e Malpighiaceae (3), constituindo $60 \%$ das espécies amostradas. A família Poaceae apresentou o maior número de espécies herbáceas (8), seguida de Asteraceae (5). Entre as arbustivas, Piperaceae (7) e Rubiaceae (5) foram as famílias mais ricas (Tab. 1). No entorno da mata, foram observadas ainda Gomphrena celosioides Mart. (Amaranthaceae), Bidens pilosa L., Emilia sagittata DC., Emilia sonchifolia (L.) DC., Hypochaeris radicata L., Taraxacum officinale Weber ex F.H. Wigg. (Asteracaeae) e Leonotis nepetifolia (L.) R. Br.
(Lamiaceae), consideradas ervas invasoras, associadas a ambientes antropizados. No interior do fragmento foram encontrados alguns cafeeiros (Coffea arabica L.).

Polinização e dispersão - Das 148 espécies coletadas na mata do Sítio São Francisco, 99 foram caracterizadas quanto à síndrome de polinização, e 56 quanto à de dispersão (Tab. 1). Ocorreu grande variedade de síndromes de polinização, o que deve estar relacionado à diversidade de espécies vegetais presentes no fragmento, nos diferentes estratos.

A síndrome de polinização mais freqüente foi a melitofilia (73\%), seguida da anemofilia (14\%) e da miiofilia (11\%). Outras síndromes ocorreram em frequiências menores: psicofilia (5\%), ornitofilia (4\%), falenofilia (3\%) e quiropterofilia (2\%). Para algumas espécies, sugeriu-se a ocorrência de ambofilia (Tab. 1).

A melitofilia foi a síndrome mais comum em todos os hábitos (Fig. 2) e em todos os estratos (Fig. 3), predominando no sub-bosque. A miiofilia apresenta o mesmo padrão que a melitofilia, ou seja, a polinização por moscas distribui-se regularmente entre os quatro hábitos, apresentando tendência de maior ocorrência em arbustos (Fig. 2), que ocupam, em geral, o subbosque e a beira de mata (Fig. 3). A anemofilia foi constatada mais em arbustos e ervas (Fig. 2) que ocupam, em sua maioria, o sub-bosque e, secundariamente, a borda (Fig. 3).

Com relação à dispersão, a síndrome mais freqüente foi a zoocoria (63\%), seguida de anemocoria (21\%) e autocoria (18\%). A zoocoria foi mais frequiente em árvores, arbustos e ervas (Fig. 4), a maioria do sub-bosque (Fig. 5). Por outro lado, a anemocoria foi muito frequiente em lianas (Fig. 4), e ocorreu em todos os estratos, com predomínio no estrato superior (Fig. 5). A autocoria ocorre em todos os hábitos (Fig. 4) e em todos os ambientes (Fig. 5).

Comparação florística - A comparação da composição florística do estrato arbóreo do fragmento do Sítio São Francisco com outros sete levantamentos realizados em matas do município de Campinas (Tab. 2) resultou numa matriz de presença e ausência de 388 binômios, dos quais $214(55 \%)$ ocorreram apenas em uma localidade e foram eliminados. Assim, a matriz de similaridade resultante contou com 174 espécies. O dendrograma de similaridade mostrou a formação de dois grupos principais, com apenas $10 \%$ de similaridade. O primeiro é constituído pelas matas higrófilas do Centro Experimental de Campinas (IAC) e Santa Genebra - brejo (SG-b). O segundo é formado pelas matas semidecíduas, com três subgrupos, dos quais um 
Tabela 1. Relação das famílias e espécies encontradas na mata do Sítio São Francisco, Campinas, SP, Brasil. Hábito (av = árvore, $\mathrm{ab}=$ arbusto, $\mathrm{ae}=$ arbusto escandente, er = erva e li = liana), ambiente (es = estrato superior, $\mathrm{sb}=$ sub-bosque e bm = beira de mata), síndrome de polinização $(\mathrm{an}=$ anemofilia, fa = falenofilia, $\mathrm{me}=$ melitofilia, $\mathrm{mi}=$ miiofilia, or $=$ ornitofilia, $\mathrm{ps}=$ psicofilia, qi = quiropterofilia $)$ e síndrome de dispersão (zo = zoocoria, ac = anemocoria e au = autocoria); número dos coletores $(\mathrm{A}=\mathrm{Ahn}$ et al., $\mathrm{C}=\mathrm{Constâncio} \mathrm{et} \mathrm{al.,}$ $\mathrm{S}=$ Spinelli et al. ); * material vegetativo.

\begin{tabular}{|c|c|c|c|c|c|}
\hline Família/Espécie & Hábito & Ambiente & $\begin{array}{l}\text { Síndrome de } \\
\text { polinização }\end{array}$ & $\begin{array}{l}\text { Síndrome de } \\
\text { dispersão }\end{array}$ & $\begin{array}{c}\text { Número dos } \\
\text { coletores }\end{array}$ \\
\hline \multicolumn{6}{|l|}{ ACANTHACEAE } \\
\hline Ruellia sanguinea Griseb. & er & $\mathrm{sb}$ & ps, or & - & S261 \\
\hline \multicolumn{6}{|l|}{ AMARANTHACEAE } \\
\hline Alternanthera tenella Colla & er & $\mathrm{sb}$ & an & - & A40 \\
\hline Chamissoa altissima (Jacq.) Kunth & li & $\mathrm{sb}$ & me, mi & - & A85 \\
\hline \multicolumn{6}{|l|}{ ANACARDIACEAE } \\
\hline Tapirira guianensis Aubl. & av & $\mathrm{sb}$ & me, mi & - & $\mathrm{C} 134, \mathrm{C} 135$ \\
\hline \multicolumn{6}{|l|}{ APOCYNACEAE } \\
\hline Aspidosperma cylindrocarpon Müll. Arg.* & av & es & - & - & - \\
\hline Condylocarpon isthmicum (Vell.) A. DC.* & li & $\mathrm{bm}$ & - & - & A11 \\
\hline \multicolumn{6}{|l|}{ ARALIACEAE } \\
\hline Dendropanax cuneatus (DC.) Decne. \& Planch. & av & $\mathrm{sb}$ & - & zo & C129 \\
\hline \multicolumn{6}{|l|}{ ASTERACEAE } \\
\hline Ageratum conyzoides L. & er & bm & me & - & S351 \\
\hline Chaptalia nutans (L.) Pol. & er & $\mathrm{sb}$ & me & - & $\mathrm{S} 231, \mathrm{~S} 233$ \\
\hline Dasyphyllum aff. brasiliense (Spreng.) Cabrera & ae & bm & me & - & S245 \\
\hline Elephantopus mollis Kunth & er & $\mathrm{sb}$ & - & - & As/n \\
\hline Eupatorium pauciflorum Kunth & er & - & - & - & $\mathrm{C} 187$ \\
\hline Mikania sp. & li & $\mathrm{sb}$ & me & - & $\mathrm{C} 128$ \\
\hline Orthopappus angustifolius (Sw.) Gleason & er & $\mathrm{sb}$ & me & - & A34 \\
\hline \multicolumn{6}{|l|}{ BALANOPHORACEAE } \\
\hline \multirow{2}{*}{\multicolumn{6}{|c|}{ BIGNONIACEAE }} \\
\hline & & & & & \\
\hline Adenocalymma bracteatum (Cham.) DC. & li & es & me & $\mathrm{ac}$ & C138 \\
\hline A. marginatum (Cham.) DC. & li & bm & me & $\mathrm{ac}$ & $\mathrm{S} 242, \mathrm{~S} 243$ \\
\hline Anemopaegma chamberlaynii (Sims) Bureau \& K. Schum. & 1. li & es & - & - & C201 \\
\hline Arrabidaea sceptrum (Cham.) Sandwith & li & bm & me & - & $\mathrm{C} 156$ \\
\hline A. triplinervia (Mart. ex DC.) Baill. ex Bureau & li & es & me & $\mathrm{ac}$ & C169, S220 \\
\hline Cuspidaria convoluta (Vell.) A.H. Gentry & li & es & - & $\mathrm{ac}$ & A97 \\
\hline Lundia obliqua Sonder & li & es & me & - & A41 \\
\hline Pyrostegia venusta (Ker Gawl.) Miers & li & es & or & - & S192 \\
\hline Stizophyllum perforatum (Cham.) Miers & li & bm & me & $\mathrm{ac}$ & S204, S229 \\
\hline Tynanthus sp. & li & es & - & $\mathrm{ac}$ & S219 \\
\hline Zeyheria tuberculosa (Vell.) Bureau* & av & es & - & - & - \\
\hline Indeterminada $1^{*}$ & li & $\mathrm{sb}$ & - & - & A6 \\
\hline Indeterminada $2 *$ & li & $\mathrm{sb}$ & - & - & A9 \\
\hline Indeterminada $3 *$ & li & $\mathrm{sb}$ & - & - & A7 \\
\hline \multicolumn{6}{|l|}{ BORAGINACEAE } \\
\hline Heliotropium transalpinum Vell. & er & bm & me & zo & A38 \\
\hline Tournefortia paniculata Cham. & er & $\mathrm{bm}$ & me & zo & $\mathrm{C} 180, \mathrm{~S} 212, \mathrm{~S} 244$ \\
\hline \multicolumn{6}{|l|}{ CACTACEAE } \\
\hline Pereskia aculeata Mill. & li & bm & me & zo & A88, S216, S221 \\
\hline Rhipsalis cereuscula Haw. & er & $\mathrm{sb}$ & - & - & A8 \\
\hline \multicolumn{6}{|l|}{ CELASTRACEAE } \\
\hline Maytenus aquifolium Mart. & $\mathrm{ab}$ & $\mathrm{sb}$ & me & - & C133 \\
\hline \multicolumn{6}{|l|}{ CONVOLVULACEAE } \\
\hline \multirow{2}{*}{\multicolumn{6}{|c|}{ CUCURBITACEAE }} \\
\hline & & & & & \\
\hline Anguria triphylla Miq. & li & bm & me & - & S196 \\
\hline Momordica charantia L. & li & $\mathrm{bm}$ & me & zo & $\mathrm{C} 186$ \\
\hline \multicolumn{6}{|l|}{ CYPERACEAE } \\
\hline Cyperus ferax Rich. & er & bm & an & - & $\mathrm{S} 250$ \\
\hline Scleria latifolia $\mathrm{Sw}$. & er & $\mathrm{sb}$ & - & - & A18 \\
\hline
\end{tabular}


Tabela 1 (continuação)

\begin{tabular}{|c|c|c|c|c|c|}
\hline Família/Espécie & Hábito & Ambiente & $\begin{array}{l}\text { Síndrome de } \\
\text { polinização }\end{array}$ & $\begin{array}{l}\text { Síndrome de } \\
\text { dispersão }\end{array}$ & $\begin{array}{c}\text { Número dos } \\
\text { coletores }\end{array}$ \\
\hline \multicolumn{6}{|l|}{ EUPHORBIACEAE } \\
\hline Acalypha gracilis Müll. Arg. & er & bm & - & - & $\mathrm{A} 19, \mathrm{~A} 28$ \\
\hline Actinostemon communis (Müll. Arg.) Pax & av & $\mathrm{sb}$ & me & zo & S214 \\
\hline A. concolor (Spreng.) Müll. Arg. & av & $\mathrm{sb}$ & - & zo & $\mathrm{C} 175$ \\
\hline Croton floribundus Spreng. & av & $\mathrm{sb}$ & me & - & C182, S239 \\
\hline C. glandulosus $\mathrm{L}$. & er & bm & me & - & $\mathrm{S} 248$ \\
\hline C. priscus Croizat & av & es & me & zo & $\mathrm{C} 177, \mathrm{~S} 217, \mathrm{~S} 223$ \\
\hline C. urucurana Baill. & av & es & me & $\mathrm{au}$ & A24, A92, \\
\hline Dalechampia pentaphylla Lam. & li & es & me & - & S235 \\
\hline D. triphylla Lam. & li & bm & - & $\mathrm{au}$ & A118, C184 \\
\hline Euphorbia heterophylla L. & er & bm & - & zo & A44 \\
\hline Mabea fistulifera Mart. & av & es & qi & zo & A54, S202 \\
\hline Sebastiania brasiliensis Spreng. & av & $\mathrm{sb}$ & - & zo & $\mathrm{C} 160$ \\
\hline S. klotzschiana (Müll. Arg.) Müll. Arg. & av & $\mathrm{sb}$ & - & zo & A93, S195 \\
\hline \multicolumn{6}{|l|}{ FABACEAE } \\
\hline Bauhinia sp.* & li & $\mathrm{sb}$ & - & - & A5 \\
\hline Centrosema pubescens Benth. & li & es & me, ps & - & A95 \\
\hline Copaifera langsdorffii Desf.* & av & es & - & - & - \\
\hline Crotalaria juncea $\mathrm{L}$. & er & bm & me & - & A55 \\
\hline Erythrina falcata Benth. & av & es & or & - & $\mathrm{C} 131$ \\
\hline Hymenaea courbaril L.* & av & es & - & $\mathrm{au}, \mathrm{zo}$ & - \\
\hline Inga marginata Willd. & av & $\mathrm{sb}$ & fa & zo & C136 \\
\hline Piptadenia gonoacantha (Mart.) J.F. Macbr. & av & $\mathrm{sb}$ & fa & $\mathrm{ac}$ & S227 \\
\hline Senna hirsuta (L.) H.S. Irwin \& Barneby & av & bm & me & $\mathrm{au}$ & A36 \\
\hline S. macranthera (DC. ex Collad.) H.S. Irwin \& Barneby & av & bm & me & - & S260 \\
\hline \multicolumn{6}{|l|}{ LAMIACEAE } \\
\hline Hyptis suaveolens (L.) Poit. & er & bm & me & - & A39 \\
\hline Leonurus sibiricus L. & er & bm & me & - & $\mathrm{A} 45, \mathrm{~A} 82, \mathrm{~A} 115$ \\
\hline \multicolumn{6}{|l|}{ LAURACEAE } \\
\hline Endlicheria paniculata (Spreng.) J.F. Macbr. & av & $\mathrm{sb}$ & me & - & $\mathrm{S} 234$ \\
\hline \multicolumn{6}{|l|}{ LECYTHIDACEAE } \\
\hline Cariniana estrellensis (Raddi) Kuntze & av & es & me & $\mathrm{ac}$ & A96, S191 \\
\hline Cariniana legalis (Mart.) Kuntze* & av & es & - & - & - \\
\hline \multicolumn{6}{|l|}{ MALPIGHIACEAE } \\
\hline Dicella bracteosa (A. Juss.) Griseb. & li & es & me & zo & S218 \\
\hline Heteropterys dumetorum (Griseb.) Nied. & li & bm & me & $\mathrm{ac}$ & A42, A103 \\
\hline Stigmaphyllon lalandianum A. Juss. & li & es & me & - & S254 \\
\hline \multicolumn{6}{|l|}{ MALVACEAE } \\
\hline Abutilon peltatum K. Schum. & $a b$ & $\mathrm{sb}$ & qi, fa & - & A107 \\
\hline Guazuma ulmifolia Lam. & av & bm & me & - & S205 \\
\hline Pavonia communis A. St.-Hil. & $a b$ & bm & - & - & A20 \\
\hline Triumfetta bartramia $\mathrm{L}$. & er & $\mathrm{sb}$ & an & - & $\mathrm{Cs} / \mathrm{n}$ \\
\hline T. semitriloba Jacq. & er & $\mathrm{sb}$ & me & - & $\mathrm{Cs} / \mathrm{n}$ \\
\hline \multicolumn{6}{|l|}{ MELASTOMATACEAE } \\
\hline Leandra sp. & $\mathrm{ab}$ & $\mathrm{sb}$ & me & zo & C130, S197 \\
\hline Miconia cinnamomifolia (DC.) Naudin & av & $\mathrm{sb}$ & me & - & A12, A89 \\
\hline M. hymenonervia (Raddi) Cogn. & $a b$ & $\mathrm{sb}$ & me & zo & $\mathrm{C} 126, \mathrm{C} 174$ \\
\hline M. minutiflora (Bonpl.) DC. & av & $\mathrm{sb}$ & me & - & S257 \\
\hline Ossaea amygdaloides (Mart. \& Schr.) Triana & $a b$ & $\mathrm{sb}$ & - & zo & A161 \\
\hline \multicolumn{6}{|l|}{ MELIACEAE } \\
\hline Cabralea canjerana (Vell.) Mart. & av & es & - & zo & $\mathrm{C} 189$ \\
\hline Guarea guidonia (L.) Sleumer & av & $\mathrm{sb}$ & ps & zo & A26 \\
\hline Trichilia catigua A. Juss. & av & $\mathrm{sb}$ & $\mathrm{mi}$ & - & A32, S237 \\
\hline T. claussenii C. DC.* & av & - & - & - & $\mathrm{C} 190$ \\
\hline T. elegans A. Juss* & av & bm & me & - & $\begin{array}{c}\mathrm{C} 176, \mathrm{~S} 206, \mathrm{~S} 208 \\
\mathrm{~S} 210, \mathrm{~S} 226\end{array}$ \\
\hline
\end{tabular}


Tabela 1 (continuação)

Família/Espécie Hábito Ambiente

Síndrome de polinização

Síndrome de dispersão

Trichilia pallida Sw.

MENISPERMACEAE

Cissampelos andromorpha DC.

MONIMIACEAE

Mollinedia elegans Tul.

MORACEAE

Ficus guaranitica Chodat

Maclura tinctoria (L.) D. Don ex Steud.

MYRSINACEAE

Ardisia warmingii (Mez) Bernacci \& Jung-Mend.

Rapanea gardneriana (A. DC.) Mez

Stylogyne laevigata (Mart.) Mez

MYRTACEAE

Myrcia aff. formosiana DC.

ORCHIDACEAE

Mesadenella cuspidata (Lindl.) Garay

Oeceoclades maculata (Lindl.) Lindl.

OXALIDACEAE

Oxalis rhombeo-ovata A. St.-Hil.

PIPERACEAE

Ottonia leptostachya Kunth

Peperomia sp.

Piper abbadianum Yunck.

$P$. aduncum L.

P. amalago $\mathrm{L}$.

P. arboreum var. latifolium (C. DC.) Yunck.

$P$. gaudichaudianum Kunth

Pothomorphe umbellata (L.) Miq.

POACEAE

Lasiacis divaricata (L.) Hitchc.

Olyra ciliatifolia Raddi.

Panicum parvifolium Lam.

$P$. cf. ovuliferum Trin.

Parodiolyra micrantha (Kunth) Davidse \& Zuloaga

Paspalum conjugatum P.J. Bergius

Setaria parviflora (Poir.) Kerguélen

S. vulpiseta (Lam.) Roem. \& Schult.

POLYGALACEAE

Polygala klotzschii Chodat

PORTULACACEAE

Talinum patens (L.) Willd.

RANUNCULACEAE

Clematis dioica $\mathrm{L}$.

RUBIACEAE

Psychotria carthagenensis Jacq.

P. cephalanta (Müll. Arg.) Standl.

$P$. hastisepala Müll. Arg.

P. mapourioides DC.

P. myriantha Müll. Arg.

Richardia brasiliensis Gomes

RUTACEAE

Esenbeckia febrifuga (A. St.-Hil.) A. Juss.ex Mart.

E. leiocarpa Engl.*

Galipea jasminiflora (A.St.-Hil.) Engl.

Metrodorea nigra A. St.-Hil.

M. stipularis Mart.

Zanthoxylum rhoifolium Lam.* av

li

$\mathrm{ab}$

av

av

$\mathrm{ab}$

$\mathrm{ab}$

av

av

er

er

er

$\mathrm{ab}$

er

$\mathrm{ab}$

$\mathrm{ab}$

$a b$

$\mathrm{ab}$

$\mathrm{ab}$

$\mathrm{ab}$

er

er

er

er

er

er

er

$a b$

er

li

$\mathrm{ab}$

$\mathrm{ab}$

$\mathrm{ab}$

$\mathrm{ab}$

$\mathrm{ab}$

er

$\mathrm{ab}$

av

av

av

av

av

me -

me

me

ZO

zo

zo

zo

$-$

me

me

me

me

me

-

an, $\mathrm{mi}$

an, mi

an, mi

an, mi

an, mi

an, mi

an

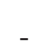

$-$

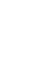

me

me

an

me

me

me

me

me

me

-

ps

me, mi

zo

au

-
C132

$s b$

$\mathrm{sb} \quad-$

es

bm

$\mathrm{sb}$

$\mathrm{sb}$

bm

$\mathrm{sb}$

$\mathrm{sb}$

$\mathrm{sb}$

$\mathrm{sb}$

$\mathrm{sb}$

$\mathrm{sb}$

$\mathrm{sb}$

$\mathrm{sb}$

$\mathrm{sb}$

$\mathrm{sb}$

bm

bm

bm

$\mathrm{sb}$

bm

$\mathrm{sb}$

$s b+b m$

bm

bm

$\mathrm{sb}$

$\mathrm{sb}$

$\mathrm{sb}$

es

$\mathrm{sb}$

$\mathrm{sb}$

$\mathrm{sb}$

$\mathrm{sb}$

$\mathrm{sb}$

bm

$\mathrm{sb}$

-

$\mathrm{sb}$

$\mathrm{sb}$

$\mathrm{sb}$

A14

C157

C262

C124

S225

S211

A2

A10, S241

A49

C123

C172

A25

S232

A52

C178

A33,S247

A31

A16

A21

A1

C185

C251

A46

A50

S215

A106

$\mathrm{Ss} / \mathrm{n}$

A259

A258

S199

A23

C249

C171

A13

au
Número dos coletores

A90, C137

A4, C188, S240

C163, S213

A53, S209, S256

A29, A 87, S 222 
Tabela 1 (continuação)

\begin{tabular}{|c|c|c|c|c|c|}
\hline Família/Espécie & Hábito & Ambiente & $\begin{array}{l}\text { Síndrome de } \\
\text { polinização }\end{array}$ & $\begin{array}{l}\text { Síndrome de } \\
\text { dispersão }\end{array}$ & $\begin{array}{c}\text { Número dos } \\
\text { coletores }\end{array}$ \\
\hline \multicolumn{6}{|l|}{ SALICACEAE } \\
\hline Casearia sylvestris $\mathrm{Sw}$. & av & $\mathrm{sb}$ & me & $\mathrm{ZO}$ & A119 \\
\hline \multicolumn{6}{|l|}{ SAPINDACEAE } \\
\hline Allophylus edulis (A. St.-Hil., Cambess. \& A. Juss.) Radlk.* & * av & $\mathrm{sb}$ & - & - & $\mathrm{Ss} / \mathrm{n}$ \\
\hline Cupania vernalis Cambess. & av & bm & me & zo & A98 \\
\hline Paullinia meliaefolia A. Juss. & li & $\mathrm{sb}$ & me & $\mathrm{ac}$ & C173, S198 S255 \\
\hline Serjania caracasana (Jacq.) Willd. & li & es,sb & me & ac & $\mathrm{A} 105, \mathrm{C} 120, \mathrm{C} 121$ \\
\hline S. fuscifolia Radlk. & li & es & me & ac & A84, A104, A114 \\
\hline S. laruotteana Cambess. & li & es & me & - & $\mathrm{C} 155$ \\
\hline Serjania sp. & li & - & - & - & $\mathrm{C} 122$ \\
\hline \multicolumn{6}{|l|}{ SOLANACEAE } \\
\hline Cestrum laevigatum Schltdl. & av & - & - & - & C127 \\
\hline C. sendtnerianum Mart. & av & es & me & - & A91 \\
\hline Nicandra physalodes Gaertn. & er & $\mathrm{bm}$ & me & au & A83 \\
\hline Solanum americanum Mill. & er & $\mathrm{sb}$ & me & - & C181 \\
\hline \multicolumn{6}{|l|}{ STYRACACEAE } \\
\hline Styrax pohlii A. DC. & av & bm & - & zo & S246 \\
\hline \multicolumn{6}{|l|}{ ULMACEAE } \\
\hline Trema micrantha (L.) Blume & av & $\mathrm{sb}$ & an & zo & A43, C158, S236 \\
\hline \multicolumn{6}{|l|}{ URTICACEAE } \\
\hline Cecropia pachystachya Trécul* & av & bm & - & - & - \\
\hline Urera baccifera (L.) Gaudich. ex Wedd. & av & $\mathrm{sb}$ & an & zo & As/n. \\
\hline \multicolumn{6}{|l|}{ VERBENACEAE } \\
\hline Aloysia virgata (Ruiz \& Pav.) Juss. & av & bm & me & - & $\mathrm{C} 170$ \\
\hline Lantana camara $\mathrm{L}$. & $a b$ & bm & me & zo & C179 \\
\hline \multicolumn{6}{|l|}{ VIOLACEAE } \\
\hline Hybanthus atropurpureus (A. St.-Hil.) Taub. & $a b$ & $\mathrm{sb}$ & me & $\mathrm{au}$ & $\begin{array}{c}\text { A22, A48, A51, } \\
\text { A116 }\end{array}$ \\
\hline \multicolumn{6}{|l|}{ VITACEAE } \\
\hline Cissus verticillata (L.) Nicolson \& C.E. Jarvis & li & es & me & au & S224 \\
\hline
\end{tabular}

é constituído pela mata do Sítio São Francisco (MSF), que possui cerca de $24 \%$ de similaridade com os demais. O segundo subgrupo é constituído pelo Bosque dos Alemães (BA), com cerca de $26 \%$ de similaridade em relação ao terceiro. Este último subgrupo é formado pelo conjunto de quatro fragmentos, agrupados dois a dois: Bosque dos Jequitibás (BJ) com a Mata da Santa Genebra (SG), com 44\% de similaridade, e Ribeirão Cachoeira (RC) com Fazenda São Vicente (SV), com 54\% (Fig. 6, Tab. 2).

\section{Discussão}

Composição florística - As famílias com maior número de espécies arbóreas no fragmento do Sítio São Francisco (Euphorbiaceae, Fabaceae, Meliaceae e Rutaceae) são coincidentes com os relatos de estudos realizados em florestas estacionais semidecíduas da região (Matthes et al. 1988; Bernacci \& Leitão Filho 1996; Santos \& Kinoshita 2003; Yamamoto et al. 2005) e de outras áreas do interior de São Paulo.

Com relação às lianas, as famílias que perfizeram $60 \%$ das espécies (Bignoniaceae, Sapindaceae e Malpighiaceae) na mata do Sítio São Francisco também figuram entre as de maior riqueza em outras florestas estacionais semideciduais do município de Campinas (Morellato \& Leitão Filho 1998 e Bernacci \& Leitão Filho 1996). Os resultados do presente estudo estão de acordo com as estimativas de Gentry (1991) de que 64\% de mais de 9.000 espécies de lianas neotropicais pertencem a apenas 12 famílias. Dentre essas famílias, Bignoniaceae, Apocynaceae, Fabaceae, Malpighiaceae e Sapindaceae contribuem com quase a metade dos gêneros e das espécies. Também Peixoto \& Gentry (1990) indicaram as Bignoniaceae como uma das famílias mais ricas e comuns nas florestas neotropicais, em especial nas matas secas.

A família Poaceae apresentou o maior número de espécies herbáceas (8), seguida de Asteraceae (5). Entre as arbustivas, Piperaceae (7) e Rubiaceae (5) 
Tabela 2. Levantamentos incluídos na comparação florística das espécies arbóreas e lianas (av = árvore; li = liana) no município de Campinas, SP, Brasil. Nome do remanescente; código; referência; metodologia empregada; tipo de formação (MP = mata paludícola; FES = floresta estacional semidecídua); área do fragmento; tipo de solo (GH = Gleissolo Háplico; AVA = Argissolo Vermelho-Amarelo; LVD = Latossolo Vermelho Distroférrico; LVA = Latossolo Vermelho-Amarelo); altitude e número de espécies amostradas (N).

\begin{tabular}{|c|c|c|c|c|c|c|c|c|}
\hline Remanescente & Código & Referência & Método & Formação & $\begin{array}{l}\text { Área } \\
\text { (ha) }\end{array}$ & Solo & $\begin{array}{l}\text { Altitude } \\
\text { (m) }\end{array}$ & $\mathrm{N}$ \\
\hline $\begin{array}{l}\text { Matas brejosas } \\
\text { contíguas à Reserva } \\
\text { Municipal de Santa } \\
\text { Genebra }\end{array}$ & SG-b & Spina 1997 & levantamento florístico & MP & 12,4 & $\mathrm{GH}$ & $580-610$ & $\begin{array}{c}66 \mathrm{av} \\
27 \mathrm{li}\end{array}$ \\
\hline $\begin{array}{l}\text { Centro Experimental } \\
\text { de Campinas - IAC }\end{array}$ & IAC & Torres et al. 1994 & censo (DAP $\geq 5 \mathrm{~cm}$ ) & MP & 0,87 & $\mathrm{GH}$ & 660 & 33 av \\
\hline Fazenda São Vicente & SV & Bernacci 1992 & parcela $(\mathrm{PAP} \geq 15 \mathrm{~cm})$ & FES & 68,96 & AVA & $625-675$ & $\begin{array}{c}133 \mathrm{av} \\
69 \mathrm{li}\end{array}$ \\
\hline $\begin{array}{l}\text { Reserva Municipal } \\
\text { de Santa Genebra }\end{array}$ & SG & Morellato 1991 & levantamento florístico & FES & 250,36 & LVD & 670 & $\begin{array}{l}96 \text { av1 } \\
35 \text { li }\end{array}$ \\
\hline $\begin{array}{l}\text { Mata do Ribeirão } \\
\text { Cachoeira }\end{array}$ & $\mathrm{RC}$ & $\begin{array}{c}\text { Santos \& } \\
\text { Kinoshita } 2003\end{array}$ & $\begin{array}{l}\text { levantamento florístico } \\
(\mathrm{PAP} \geq 9 \mathrm{~cm})\end{array}$ & FES & 244,89 & AVA & $630-756$ & $162 \mathrm{av}$ \\
\hline Bosque dos Jequitibás & $\mathrm{BJ}$ & Matthes 1980 & censo(DAP $\geq 5 \mathrm{~cm})$ & FES & 2,33 & AVA & 700 & $178 \mathrm{av}$ \\
\hline Bosque dos Alemães & BA & $\begin{array}{l}\text { Cielo Filho \& } \\
\text { Santin } 2002\end{array}$ & censo $(\mathrm{PAP} \geq 15 \mathrm{~cm})$ & FES & 2,05 & LVA & 685 & $105 \mathrm{av}$ \\
\hline $\begin{array}{l}\text { Mata do Sítio } \\
\text { São Francisco }\end{array}$ & MSF & presente estudo & $\begin{array}{l}\text { levantamento florístico } \\
\quad(\mathrm{DAP} \geq 5 \mathrm{~cm})\end{array}$ & FES & 3,27 & LVD & $600-700$ & $\begin{array}{c}50 \mathrm{av} \\
31 \mathrm{li}\end{array}$ \\
\hline
\end{tabular}

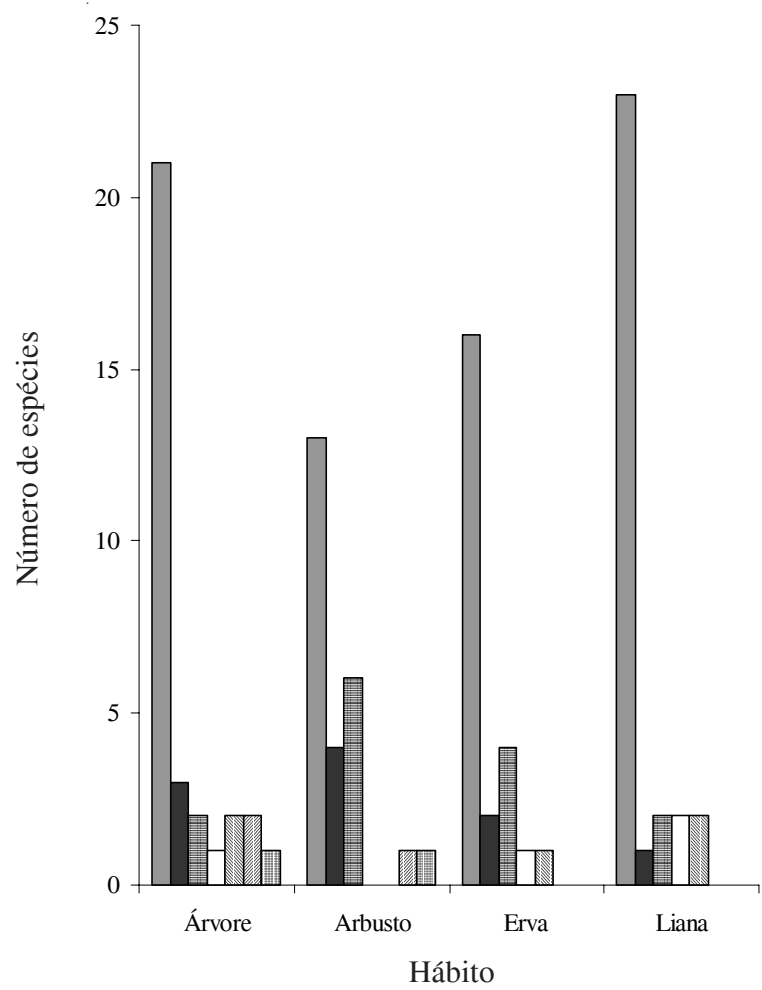

Figura 2. Distribuição das síndromes de polinização relacionadas com o hábito na mata do Sítio São Francisco, Campinas, SP, Brasil. $\square=$ melitofilia; $\mathbf{\square}=$ miifolia; 圆 = anemofilia; $\square=$ ornitofilia;

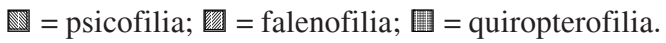

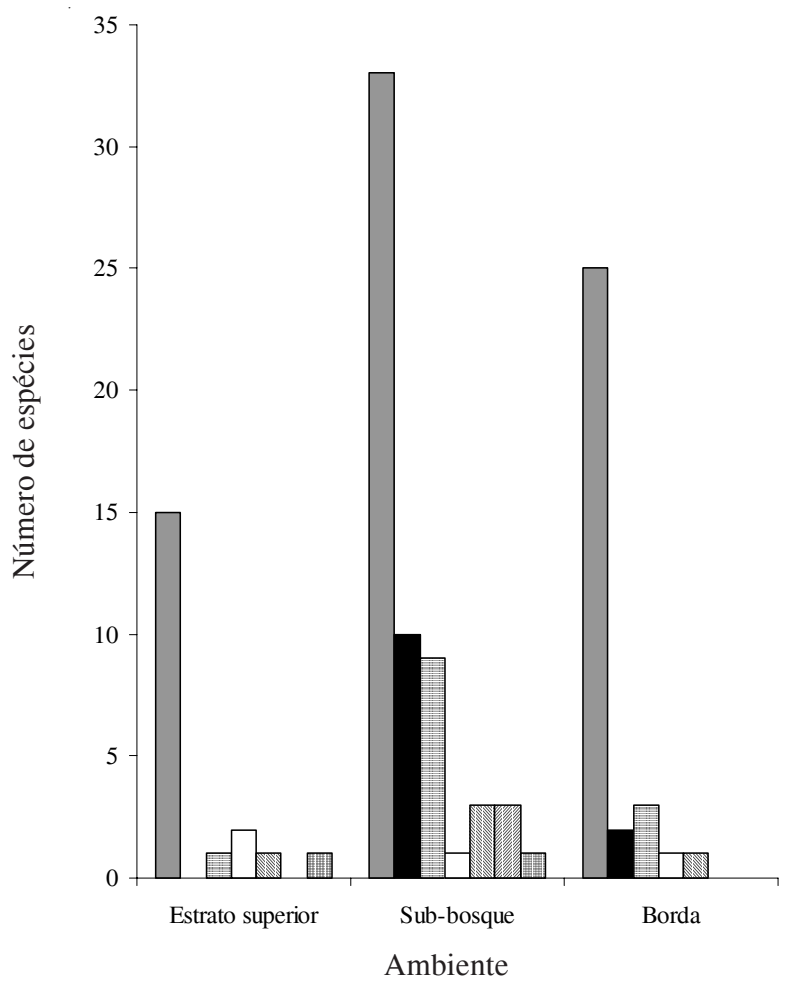

Figura 3. Distribuição das síndromes de polinização relacionadas com o ambiente ocupado na mata do Sítio São Francisco, Campinas,

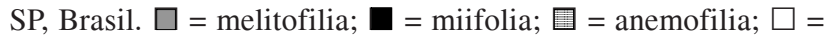

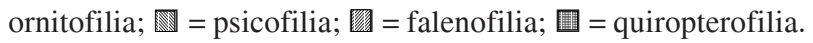


foram as famílias mais ricas (Tab. 1). Essas famílias também foram as mais freqüentemente relatadas em outros fragmentos de floresta estacionais semideciduais na região de Campinas (Bernacci \& Leitão Filho 1996, Salis et al. 1996 e Yamamoto et al. 2005). Poaceae, Piperaceae e Rubiaceae estão entre as famílias mais ricas no estrato herbáceo de comunidades de mata Atlântica no sul do país (Citadini-Zanette 1984, CitadiniZanette \& Baptista 1989, Müller \& Waechter 2001 e Negrelle 2002). Apesar destas famílias ocorrerem em todos esses fragmentos, poucas são as espécies em comum. Quando as Piperaceae estão representadas por espécies de Piper, como na mata do Sítio São Francisco, predominam no estrato arbustivo. Já na mata Atlântica no sul do país, são mais abundantes as espécies de Peperomia e, neste caso, predominam no estrato herbáceo. As espécies de Piper são consideradas importantes elementos de clareiras e do sub-bosque das florestas tropicais, pois possivelmente auxiliam na manutenção da diversidade de insetos, importantes vetores de pólen de diversas outras plantas, além de serem mutualistas com morcegos frugívoros e constituírem importante recurso alimentar para aves (Figueiredo \& Sazima 2004).

Entre as espécies arbustivas observadas, Hybanthus atropurpureus (A. St.-Hil.) Taub.

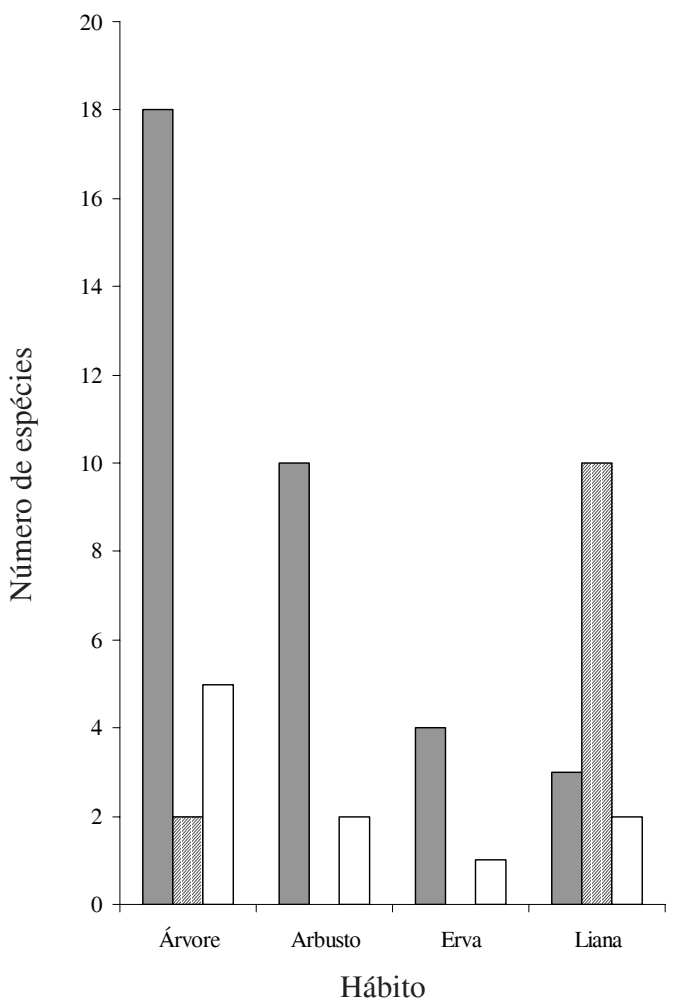

Figura 4. Distribuição das síndromes de dispersão relacionadas com o hábito na mata do Sítio São Francisco, Campinas, SP, Brasil. $\square=$ zoocoria; 蒐 = anemocoria; $\square=$ autocoria. também é citada com grande número de indivíduos na mata Santa Genebra (Salis et al. 1996), e foi observada em locais onde ocorreu fogo (L.A.F. Matthes, dados não publicados), sugerindo que pode ser indicadora de perturbações. Na mata do Sítio São Francisco, esta espécie predominou próximo às trilhas e clareiras, assim como Heliotropium transalpinum Vell. e Oxalis rhombeo-ovata A. St.-Hil. A ocorrência de indivíduos de Coffea arabica no subbosque pode ser explicada pelo fato de que na região, até a década de 1950, os viveiros de mudas de café eram feitos no interior das matas (Martins 1991).

Deve-se considerar ainda que, devido à falta de padronização na metodologia empregada e na classificação dos hábitos do estrato herbáceo-arbustivo, a comparação dos resultados de diferentes trabalhos deve ser considerada com cautela. No presente estudo foram considerados apenas as ervas e arbustos em estado reprodutivo, enquanto em outros levantamentos foram incluídos plântulas e indivíduos muito jovens de espécies arbóreas.

Polinização e dispersão - Em florestas tropicais a polinização por abelhas e vespas tem sido o sistema predominante, o que também foi observado no fragmento do Sítio São Francisco $(73 \%)$ e na mata de Santa Genebra (45,7\%, Morellato 1995a).

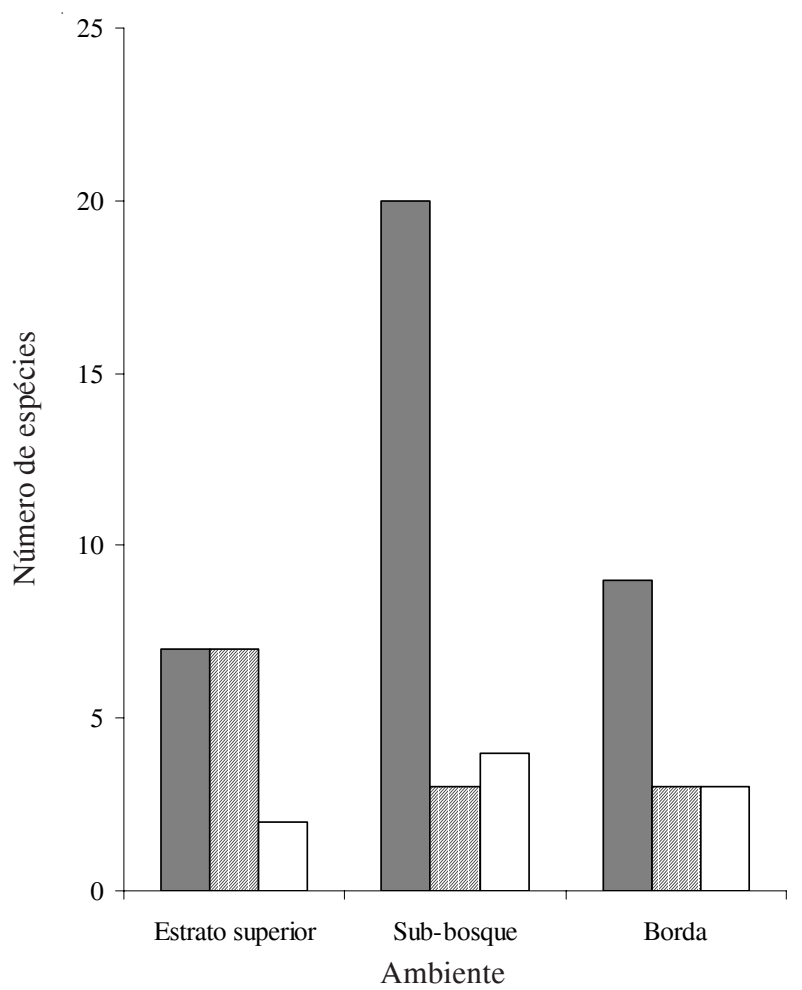

Figura 5. Distribuição das síndromes de dispersão relacionados com o ambiente ocupado na mata do Sítio São Francisco, Campinas, SP, Brasil. $\square$ = zoocoria; 范 = anemocoria; $\square$ = autocoria. 
Média de grupo (UPGMA)

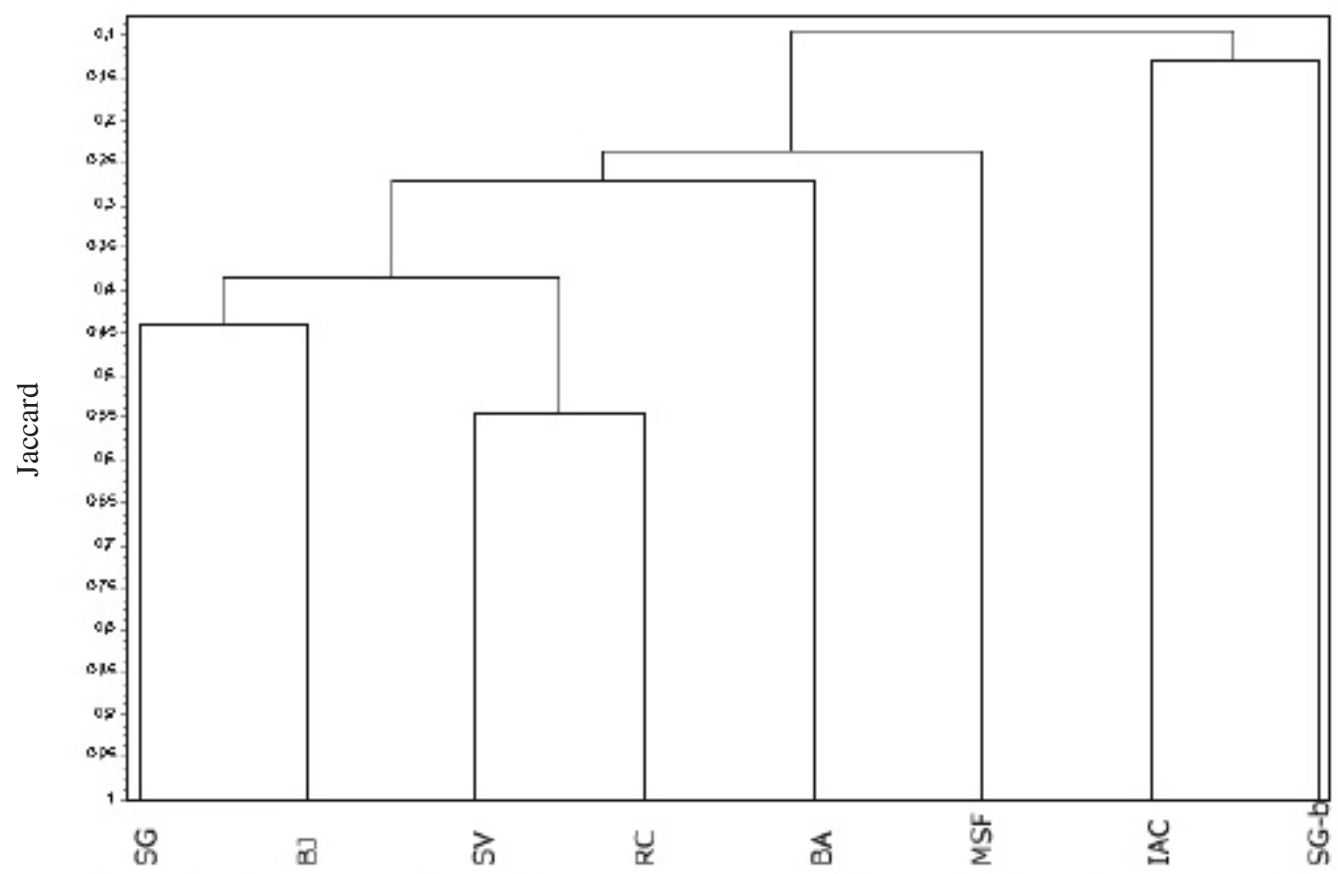

Figura 6. Dendrograma de análise de agrupamento obtido por índice de Jaccard e média de grupo (UPGMA), aplicado às espécies arbóreas amostradas nos oito remanescentes de mata no município de Campinas, SP, Brasil. Os códigos das localidades encontram-se na Tabela 2.

L.F. Yamamoto (dados não publicados) encontrou $46,9 \%$ de polinização por abelhas e por outros pequenos insetos em todos os estratos, tanto na borda como no interior da mata. As abelhas sociais são os polinizadores mais versáteis e ativos e, conseqüentemente, os mais conhecidos, obtendo recursos para si e para a prole em plantas com diferentes atributos florais (Faegri \& Pijl 1976). Algumas abelhas são capazes de vibrar anteras para a retirada de pólen em flores com deiscência poricida (Buchmann 1983), como em espécies de Senna e em Solanum americanum Mill., ocorrentes no fragmento do Sítio São Francisco.

Provavelmente a alta porcentagem de plantas polinizadas por vento (14\%) deve-se ao levantamento de todos os hábitos, incluindo espécies herbáceas de Poaceae e Cyperaceae, predominantemente anemófilas. Segundo Bullock (1994), a ocorrência deste tipo de polinização nas espécies arbóreas das florestas tropicais tem sido subestimada. Como exemplo, o autor cita a polinização efetiva pelo vento de uma espécie de Croton, cujas flores até produzem néctar e são visitadas por muitos insetos. Segundo Faegri \& Pijl (1976), a anemofilia é considerada uma condição derivada da entomofilia.

As menores freqüências da miiofilia (11\%), psicofilia (5\%), ornitofilia (4\%), falenofilia (3\%) e quiropterofilia (2\%) observadas no fragmento do Sítio São Francisco são equivalentes às obtidas na região (L.F. Yamamoto, dados não publicados). Entretanto, a autora encontrou valor bem superior para falenofilia $(12,4 \%)$, estudando espécies arbustivo-arbóreas em mata de altitude bastante perturbada, no município de Pedreira.

Negrelle (2002), estudando síndromes de polinização na Reserva Volta Velha, um fragmento de Mata Atlântica no sul do país, mencionou 94,8\% de espécies entomófilas (sem especificar os diferentes tipos de insetos), 3,2\% de ornitófilas, $1 \%$ de quiropterófilas e $1 \%$ de anemófilas. Na mata do Sítio São Francisco, as espécies entomófilas somaram 92\%, sendo também a síndrome mais comum. A maior diferença residiu na frequiência de anemofilia, bem maior no nosso estudo (12\%). Uma explicação poderia ser as diferenças nas condições abióticas que levariam às diferenças na composição florística dos fragmentos considerados.

Muitas espécies nas regiões tropicais e temperadas podem apresentar mais de uma síndrome de polinização, e a interação planta-polinizador é uma relação flexível (Proctor et al. 1996). Flores polinizadas por abelhas, mesmo quando especializadas, podem ser polinizadas por mariposas e borboletas e as plantas 
ornitófilas também podem ser polinizadas por abelhas e vice-versa. Tanto na anemofilia como na entomofolia, que envolve diferentes adaptações florais, a polinização pode ser intercambiável em alguns grupos de plantas, como em Plantago (Proctor et al. 1996). Em Piper, Figueiredo \& Sazima (2004) citam a ocorrência de ambofilia, com espécies podendo ser polinizadas por diferentes tipos de insetos (Diptera, Hymenoptera, Lepidoptera e Coleoptera) e também pelo vento, o que poderia compensar uma possível deficiência sazonal de insetos polinizadores.

A alta freqüência e ocorrência de plantas melitófilas em todos os estratos e tipos de hábitos da mata do Sítio São Francisco já havia sido relatada em outras florestas tropicais. Bawa et al. (1985), num levantamento feito em árvores de uma floresta tropical úmida, na Costa Rica, encontrou $52 \%$ e $37 \%$ de espécies polinizadas por abelhas no dossel e sub-dossel, respectivamente. Por outro lado, L.F. Yamamoto (dados não publicados) não encontrou diferenças significativas na distribuição das síndromes de polinização entre os estratos, nem entre a borda e o interior dos fragmentos.

L.F. Yamamoto (dados não publicados) observou a ocorrência de anemofilia apenas na borda dos fragmentos. Por outro lado, no fragmento do Sítio São Francisco essa síndrome foi mais freqüente no subbosque do que na borda, área em que se espera que a ação do vento sobre os grãos de pólen seja mais eficiente. A diferença nos resultados pode ser atribuída ao fato das espécies herbáceas e arbustivas da mata do Sítio São Francisco terem sido coletadas principalmente ao longo da trilha que corta o fragmento.

As porcentagens de dispersão por zoocoria (63\%), anemocoria (21\%) e autocoria (18\%) foram semelhantes às encontradas por Spina et al. (2001). Na mata Santa Genebra, Morellato (1995b) encontrou apenas $40,8 \%$ de zoocoria e maior porcentagem de anemocoria (46,9\%). Já Negrelle (2002) obteve 89,6\% de zoocoria e baixos valores para anemocoria e autocoria na Reserva Volta Velha, indicando um padrão diferenciado entre um fragmento de mata Atlântica e de floresta estacional semidecídua. A frequiência e a distribuição das espécies zoocóricas na mata do Sítio São Francisco estão de acordo com a literatura, considerando as florestas tropicais. Na vegetação tropical estacional, a zoocoria é mais freqüente que a anemocoria, ocorrendo principalmente em árvores e arbustos (Ortega 1986; Morellato \& Leitão Filho 1991). Vários autores têm observado que as espécies zoocóricas predominam nos estratos inferiores
(Morellato \& Leitão Filho 1991) mas, contrariando essa generalização, L.F. Yamamoto (dados não publicados) constatou o predomínio da zoocoria em todos os estratos no interior da mata, e também no dossel.

A ocorrência da anemocoria em árvores altas e em lianas que ocupam o dossel parece estar associada a uma maior exposição das diásporas à ação do vento e, portanto, a melhores chances de dispersão (Howe \& Smallwood 1982; Wikander 1984; Roth 1987; Morellato \& Leitão Filho 1991; Talora \& Morellato 2000; Spina et al. 2001). Em Mata Atlântica (Negrelle 2002), a pouca ocorrência de anemocoria é explicada pelas condições mais úmidas do ambiente, o que dificultaria a dispersão de diásporas, quando comparado com a mata do Sítio São Francisco, uma floresta estacional semidecídua.

A distribuição da autocoria em todos os estratos e hábitos no fragmento do Sítio São Francisco foi diferente da encontrada por L.F. Yamamoto (dados não publicados), que observou autocoria em todos os estratos na borda, mas no interior, apenas no estrato superior. Esses ambientes são considerados como favoráveis à ocorrência da autocoria, pois supõe-se que seja vantajoso que as diásporas caiam de uma grande altura (Roth 1987) ou que as plantas estejam em ambiente aberto (L.F. Yamamoto, dados não publicados).

Mesmo sendo uma área bastante pequena, a mata do Sítio São Francisco agrega uma grande biodiversidade, não só de plantas como também de animais, incluindo aves e mamíferos, como lebres, cachorro-do-mato, tatus, gambás e outros marsupiais (J.H.A. Dutilh, com. pess.). A alta porcentagem de espécies polinizadas e dispersas por animais ressalta o papel das interações mutualísticas animais-plantas na manutenção dos ecossistemas naturais.

A mata do Sítio São Francisco e outros fragmentos do município de Campinas - Dos oito fragmentos comparados, quatro são pequenos, com menos de 10 ha, sendo dois remanescentes urbanos, sob grande pressão antrópica, especialmente o Bosque dos Jequitibás. Entre os maiores remanescentes, as matas de Santa Genebra e do Ribeirão Cachoeira (Tab. 2), apenas esta última pode ser considerada em bom estado de conservação. A mata do Ribeirão Cachoeira está localizada na área rural, junto a um condomínio cujo acesso é restrito aos moradores locais, fatores que têm contribuído para a sua conservação.

A diferenciação dos dois principais agrupamentos (Fig. 6), matas estacionais semidecíduas e matas 
higrófilas, deve-se às características de umidade do solo. Nas matas higrófilas, o encharcamento permanente do solo é considerado o principal fator abiótico limitante à ocorrência das espécies vegetais, selecionando um conjunto particular de plantas (Torres et al. 1994; Ivanauskas et al. 1997).

A mata do Sítio São Francisco mostrou similaridade intermediária entre o grupo das matas higrófilas e das outras matas estacionais semidecíduas. Observaram-se várias espécies comuns à mata do Sítio São Francisco e às matas paludícolas, algumas delas típicas de solos encharcados (Torres et al. 1994; Ivanauskas et al. 1997; A.P. Spina, dados não publicados): Cecropia pachystachya Trécul, Croton urucurana Baill., Dendropanax cuneatus (DC.) Decne. \& Planch, Ficus guaranitica Chodat, Guarea guidonia (L.) Sleumer, Sebastiania klotzschiana (Müll. Arg.) Müll. Arg. e Styrax pohlii A. DC. Estas espécies foram encontradas na área brejosa na baixada do fragmento, onde o solo apresenta alta umidade, principalmente no período de chuvas. A riqueza florística encontrada em um fragmento pequeno, como a mata do Sítio São Francisco, pode, assim, estar associada à diversidade de micro-ambientes, com áreas brejosas e de clareiras naturais em diferentes estágios de regeneração.

Observou-se que Dendropanax cuneatus ocorreu em sete dos oito levantamentos comparados no município de Campinas. Outras 11 espécies foram encontradas em seis remanescentes e 18 espécies em cinco deles. Por outro lado, Cestrum sendtnerianum Mart., Mabea fistulifera Mart., Miconia cinnamomifolia (DC.) Naudin, Miconia minutiflora (Bonpl.) DC., Stylogyne laevigata (Mart.) Mez (Tab. 1) foram encontradas apenas na mata do Sítio São Francisco. A ausência destas espécies nos outros levantamentos de Campinas pode estar relacionada ao critério de inclusão utilizado nos diferentes estudos (Tab. 2).

Além das diferenças florísticas encontradas entre os oito fragmentos citados na Tab. 2, observou-se uma diferença de todos eles (de $35 \%$ a $55 \%$ ) em relação ao estudo de D.A. Santin (dados não publicados), que realizou levantamento expedito de 159 fragmentos da vegetação remanescente de Campinas.

Dentre as 35 espécies de lianas encontradas na mata do Sítio São Francisco, nenhuma ocorreu simultaneamente nos levantamentos comparados no município. Apenas 11 ocorreram em três dos quatro fragmentos e sete foram exclusivas: Arrabidaea sceptrum (Cham.) Sandwith, Centrosema pubescens
Benth., Cissampelos andromorpha DC., Cuspidaria convoluta (Vell.) A.H. Gentry, Heteropterys dumetorum (Griseb.) Nied., Serjania fuscifolia Radlk. e S. laruotteana Cambess.

A comparação florística entre os fragmentos tem limitações em função de inúmeros fatores, entre eles: diferenças na metodologia empregada, tipo de solo, altitude, tamanho (Tab. 2) e no estado de conservação, o grau de isolamento e as características do entorno destes fragmentos. Mesmo considerando estas limitações, os resultados reforçam a importância e a necessidade de conservação dos remanescentes de vegetação nativa do município de Campinas, dada a sua riqueza florística e a ocorrência de espécies exclusivas em cada um deles, ainda que pequenos, perturbados e próximos da área urbana.

\section{Agradecimentos}

Aos Drs. Julie H.A. Dutilh e Eduardo De Capittani, pela possibilidade de estudar a mata do Sítio São Francisco e pelo apoio logístico; aos especialistas que auxiliaram na identificação dos materiais, em especial ao Prof. Jorge Y. Tamashiro (diversas famílias), Dra. Sigrid L. Jung-Mendaçolli (Rubiaceae) e Dra. Hilda M. Longhi-Wagner (Poaceae); à FAPESP, pelo apoio financeiro.

\section{Referências bibliográficas}

APG II. 2003. An update of the Angiosperm Phylogeny Group classification for the orders and families of flowering plants: APG II. Botanical Journal of the Linnean Society 141: 399-436.

Bawa, K.S. 1990. Plant-pollinator interactions in tropical rain forest. Annual Review of Ecology and Systematics 21: 399-422.

Bawa, K.S.; Bullock, S.H.; Perry, D.R.; Coville, R.E. \& Grayum, M.H. 1985. Reproductive biology of tropical lowland rain forest tree. II. Pollination systems. American Journal of Botany 72: 346-356.

Bernacci, L.C. \& Leitão Filho, H.F. 1996. Flora fanerogâmica da floresta da Fazenda São Vicente, Campinas, SP. Revista Brasileira de Botânica 19(2): 149-164.

Bertoni, J.E.A. \& Martins, F.R. 1987. Composição florística de uma floresta ripária na Reserva Estadual de Porto Ferreira, SP. Acta Botanica Brasilica 1(1): 17-26.

Brummitt, R.K. \& Powell, C.E. 1992. Authors of plant names. Great Britain, Whiststable Litho Ltds.

Buchmann, S.L. 1983. Buzz pollination in angiosperms. Pp. 73-113. In: C.E. Jones \& R.J. Litter (eds.). Handbook of experimental pollination biology. New York, Van Nostrand \& Reinhold. 
Bullock, S.H. 1994. Wind pollination of neotropical dioecious trees. Biotropica 26(2): 172-179.

Cestaro, L.A.; Waechter, J.L. \& Baptista, L.R.M. 1986. Fitossociologia do estrato herbáceo da mata de araucária da Estação Ecológica de Aracuri, Esmeralda, RS. Hoehnea 13: 59-72.

Cielo Filho, R. \& Santin, D.A. 2002. Estudo florístico e fitossociológico de um fragmento florestal urbano Bosque dos Alemães, Campinas, SP. Revista Brasileira de Botânica 25(3): 291-301.

Citadini-Zanette, V. 1984. Composição florística e fitossociologia da vegetação herbácea terrícola de uma mata de Torres, Rio Grande do Sul, Brasil. Iheringia, Série Botânica 32: 23-62.

Citadini-Zanette, V. \& Baptista, L.R.M. 1989. Vegetação herbácea terrícola de uma comunidade florestal em Limoeiro, município de Torres, RS, Brasil. Universidade do Rio Grande do Sul. Boletim do Instituto de Biociências 45: 1-87.

Embrapa - Centro Nacional de Pesquisa de Solos. 1999. Sistema brasileiro de classificação de solos. Brasília, Embrapa Solos.

Dafni, A. 1982. Pollination ecology: a practical approach. Oxford, IRL Press.

Faegri, K. \& Pijl, L. 1976. The principles of pollination ecology. Oxford, Pergamon Press.

Figueiredo, R.A. \& Sazima, M. 2004. Pollination ecology and resource partitioning in neotropical Pipers. Pp. 33-57. In: L.A. Dyer \& A.D.N. Palmer (eds.). Piper: a model Genus for studies of Phytochemistry, Ecology and Evolution. New York, Kluwer Academic/Plenum Publishers.

Font Quer, P. 1965. Dicionário de Botanica. Barcelona, Editorial Labor S.A.

Fundação SOS Mata Atlântica \& INPE 2002. Atlas dos remanescentes florestais da Mata Atlântica no período 1995-2000. Relatório final. http:// www.sosmatatlantica.org.br/atlas2001. (Acesso em: 24/06/2005).

Gandolfi, S.; Leitão Filho, H.F. \& Bezerra, C.L.F. 1995. Levantamento florístico e caráter sucessional das espécies arbustivo-arbóreas de uma floresta estacional semidecídua no município de Guarulhos, SP. Revista Brasileira de Biologia 55(4): 753-767.

Gentry, A.H. 1991. The distribution and evolution of climbing plants. Pp. 3-49. In: F.E. Putz \& H.A. Mooney (eds.). The biology of vines. Cambridge, Cambridge University Press.

Herrera, C.M. 1996. Floral traits and adaptation to insect pollinators: a devil's advocate approach. Pp. 65-87. In: D.G. Lloyd \& S.C.H. Barrett (eds.). Floral Biology. New York, Chapman \& Hall.

Herrera, J.1998. Pollination relationships in southeastern Spanish Mediterranean shrublands. Journal of Ecology 76: $274-287$.

Howe, H.F. \& Smallwood, J. 1982. Ecology of seed dispersal. Annual Review of Ecology and Systematics 13: 201-228.

Ivanauskas, N.M.; Rodrigues, R.R. \& Nave, A.G. 1997. Aspectos ecológicos de um trecho de floresta de brejo em Itatinga, SP: florística, fitossociologia e seletividade de espécies. Revista Brasileira de Botânica 20(2): 139-153.
Koeppen, W. 1948. Climatologia. México, Buenos Aires, Ed. Fundo de Cultura Econômica.

Martins, F.R. 1991. Estrutura de uma floresta mesófila. Campinas, Editora da Universidade Estadual de Campinas.

Matthes, L.A.F.; Leitão Filho, H.F. \& Martins, F.R. 1988. Bosque dos Jequitibás (Campinas - SP): composição florística e estrutura fitossociológica do estrato arbóreo. Pp. 55-76. In: Anais do V Congresso da Sociedade Botânica de São Paulo. Botucatu, 1985.

McCall, C. \& Primack, R.B. 1992. Influence of flower characteristics, weather, time of day, and season on insect visitation rates in three plant communities. American Journal of Botany 79: 434-442.

Mello, M.H.A.; Pedro Junior, M.G.; Ortolani, A.A. \& Alfonsi, R.R. 1994. Chuva e temperatura: cem anos de observações em Campinas. Boletim Técnico do Instituto Agronômico de Campinas 154: 1-48.

Morellato, L.P.C. 1995a. As flores e seus polinizadores. Pp. 42-45. In: L.P.C. Morellato \& H.F. Leitão Filho. Ecologia e preservação de uma floresta tropical urbana - Reserva de Santa Genebra. Campinas, Editora da UNICAMP.

Morellato, L.P.C. 1995b. Frutos, frugívoros e dispersão de sementes. Pp. 64-65. In: L.P.C. Morellato \& H.F. Leitão Filho. Ecologia e preservação de uma floresta tropical urbana - Reserva de Santa Genebra. Campinas, Editora da UNICAMP.

Morellato, L.P.C. \& Leitão Filho, H.F. 1991. Padrões de frutificação e dispersão na Serra do Japi. Pp. 112-140. In: L.P.C. Morellato (org.). História Natural da Serra do Japi: ecologia e preservação de uma área florestal no sudeste do Brasil. Campinas, Editora da UNICAMP.

Morellato, L.P.C \& Leitão Filho, 1998. Levantamento florístico da comunidade de trepadeiras de uma floresta semidecídua no Sudeste do Brasil. Boletim do Museu Nacional do Rio de Janeiro, série Botânica 103: 1-15.

Müller, S.C. \& Waechter, J.L. 2001. Estrutura sinusial dos componentes herbáceo e arbustivo de uma floresta costeira subtropical. Revista Brasileira de Botânica 24(4): 395-406.

Negrelle, R.R.B. 2002. The Atlantic forest in the Volta Velha Reserve: a tropical rain forest site soutside the tropics. Biodiversity and Conservation 11: 887-919.

Oliveira, J.B.; Menck, J.R.F. \& Rotta, C.L. 1977. Levantamento semi-detalhado dos solos do estado de São Paulo. Quadrícula Campinas, mapa escala 1:100.000. Rio de Janeiro, IBGE.

Ortega, L.C.S. 1986. Études floristiques de divers stades secondaires des formations forestières du haut Parana (Paraguai Oriental). Floraison, frutificacion et dispersion des espèces forestières. Candollea 1: 121-144.

Pagano, S.N. \& Leitão Filho, H.F. 1987. Composição florística do estrato arbóreo de mata mesófila semidecídua, no município de Rio Claro (Estado de São Paulo). Revista Brasileira de Botânica 10(1): 37-47.

Pagano, S.N., Leitão Filho, H.F. \& Shepherd, G.J. 1987. Estudo fitossociológico em mata mesófila semidecídua no municipio de Rio Claro (Estado de São Paulo). Revista Brasileira de Botânica 10(1): 49-61. 
Peixoto, A.L. \& Gentry, A.H. 1990. Diversidade e composição florística da mata de tabuleiro na Reserva Florestal de Linhares (Espírito Santo, Brasil). Revista Brasileira de Botânica 13(1): 19-25.

Pijl, L. van der 1982. Principles of dispersal in higher plants. New York, Springer-Verlag.

Pielou, E.C. 1984. The interpretation of ecological data. A primer on classification and ordination. New York, Wiley.

Proctor, M.; Yeo, P. \& Lack, A. 1996. The natural history of pollination. London, Harper Collins Publishers.

Radford, A.E.; Dickinson, W.C.; Massey, J.R. \& Bell, C.R. 1974. Vascular Plant Systematics. New York and London, Harper \& Row.

Rodrigues, R.R.; Torres, R.B.; Matthes, L.A.F. \& Penha, A.S. 2004. Tree species sprouting from root buds in a Semideciduous Forest affected by fires. Brazilian Archives of Biology and Technology 47: 127-133.

Roth, I. 1987. Stratification of a tropical forest as seen in dispersal types. Dordreecht, Dr W. Junk Publishers.

Rozzi, R.; Arroyo, M.K. \& Armesto, J.J. 1997. Ecological factors affecting gene flow between populations of Anarthrophyllum cumingii (Papilionaceae) growing on equatorial-and polar-facing slopes in the Andes of Central Chile. Plant Ecology 132: 171-179.

Salis, S.M.; Zickel, C.S. \& Tamashiro, J.Y. 1996. Fitossociologia do sub-bosque da mata da Reserva Municipal de Santa Genebra, Campinas (Estado de São Paulo). Naturalia 21: 171-180.

Santos, A. C. 2002. Campinas, das origens ao futuro. Compra e venda de terra éágua e um tombamento na primeira sesmaria da Freguesia de Nossa Senhora da Conceição das Campinas do Mato Grosso de Jundiaí. Campinas, Editora da UNICAMP.

Santos, K. \& Kinoshita, L.S. 2003. Flora arbustivo-arbórea do fragmento de floresta estacional semidecidual do Ribeirão Cachoeira, município de Campinas, SP. Acta Botanica Brasilica 17(3): 325-341.
Serra Filho, R.; Cavalli, A.C.; Guillaumon, J.R.; Chiarini, J.V.; Nogueira, F.P.; Ivancko, C.M.A.M.; Barbieri, J.L.; Donzeli, P.L.; Coelho, A.G.S. \& Bittencourt, I. 1974. Levantamento da cobertura vegetal natural e do reflorestamento no estado de São Paulo. Secretaria da Agricultura. Coordenadoria de Pesquisa de recursos naturais. Instituto Florestal. Boletim Técnico 11: 1-53.

Shepherd, G.J. 2004. FITOPAC-SHELL 1.5: Manual do usuário. Campinas, Universidade Estadual de Campinas.

Smith, A.P. 1973. Stratification of temperate and tropical forest. American Naturalist 107: 671-683.

Spina, A.P.; Ferreira, W.M. \& Leitão Filho, H.F. 2001. Floração, frutificação e síndromes de dispersão de uma comunidade de floresta de brejo na região de Campinas (SP). Acta Botanica Brasilica 15(3): 349-368.

Talora, D.C. \& Morellato, P.C. 2000. Fenologia de espécies arbóreas em floresta de planície litorânea do sudeste do Brasil. Revista Brasileira de Botânica 23(1): 13-26.

Toniato, M.T.Z.; Leitão Filho, H.F. \& Rodrigues, R.R. 1998. Fitossociologia de um remanescente de floresta higrófila (mata de brejo) em Campinas, SP. Revista Brasileira de Botânica 21(2): 197-210.

Torres, R.B.; Matthes, L.A.F. \& Rodrigues, R.R. 1994. Florística e estrutura do componente arbóreo de mata de brejo de Campinas, SP. Revista Brasileira de Botânica 17(2): 189-194.

Wikander, T. 1984. Mecanismos de dispersión de diasporas de una selva decidua en Venezuela. Biotropica 16(4): 276-283.

Yamamoto, L.F.; Kinoshita, L.S. \& Martins, F.R. 2005. Florística dos componentes arbóreo e arbustivo de um trecho da Floresta Estacional Semidecídua Montana, município de Pedreira, estado de S. Paulo. Revista Brasileira de Botânica 28(1): 191-202. 